\title{
Marruecos en el pensamiento de Marcelino Domingo
}

\author{
Hussein Bouzalmate \\ Universidad Complutense, Madrid
}

\section{VIDA Y OBRA DE MARCELINO DOMINGO}

Marcelino Domingo nace en Tortosa en el año 1884, en el seno de una familia de clase media. Su padre era oficial de la guardia civil.

Su itinerario político es dilatado: ha sido profesor de primera enseñanza, diputado, político, periodista, escritor y ensayista. Colaboró en varios periódicos durante el primer tercio del presente siglo: El Pueblo de su Tortosa natal, El Poble catalá y La Publicidad de Barcelona; El Liberal, El Socialista y La Libertad de Madrid.

Sus primeros pasos en el campo de la política estuvieron influenciados, por un personaje clave en la historia política de Cataluña: Pi y Margall, impregnándose de un espíritu republicano, federal y laico.

Desde muy joven asumirá responsabilidades políticas, así en 1909 es elegido concejal del ayuntamiento de Tortosa: y en el año 1914 diputado por esa misma circunscripción, gracias a los votos de los radicales que lideraba Alejandro Lerroux. Pero luego en las Cortes actuó como republicano independiente, no sumándose a los radicales.

Junto a Francese Layret — que será asesinado- y Gabriel Alomar, personajes importantes dentro del pensamiento democrático español, funda en el año 1916 el Bloc Republicà Autonomista y su órgano de opinión La Lucha, aglutinando a elementos de la Unió Federal Nacionalista Republicana y radicales. Un año más tarde, en abril de 1917, se transfor- 
ma en el Partit Republicá Català, de cuya dirección, era miembro, M. Domingo.

Durante la huelga de agosto de 1917, que azotó a España, será detenido. encarcelado y -según testimonios- maltratado por los militares en las Atarazanas de Barcelona, sin que tenga en cuenta su condición de diputado y la inmunidad parlamentaria de que gozaba. Se le acusaba de ser uno de los instigadores de la huelga. En su encarcelamiento ha influido mucho su campaña antimilitarista de la que había hecho gala en el periódico La Lacha. Fue puesto en libertad en noviembre de 1917.

En el año 1918 es elegido de nuevo diputado, pero esta vez por la circunscripción de Barcelona. En 1929, funda el Partido Radical-Socialista.

Durante la Segunda República desempeñará cargos importantes: ministro de Instrucción Pública y de Agricultura Comercio e Industria. Hizo una gran labor a la cabeza del Ministerio de Instrucción Pública, con la construcción de unas 10.000 escuelas durante su gestión ministerial. Mientras que en el Ministerio de Agricultura despertó las iras de los agricultores al negarse a aumentar los precios de tasa del trigo importando 250.000 toneladas en el año 1932.

En noviembre de 1933 su partido se fusiona con el de Manuel Azaña, Acción Republicana, para constituir Izquierda Republicana. Fusión que se hizo a raíz del triunfo centro-derechista en las elecciones de 1933.

Formó parte de la comisión, compuesta por Fernández de los Ríos y Nicolau D'Olwer que se desplaza a Barcelona, para que Macià revocase la proclamación de la República Catalana.

En su agitada vida tuvo tiempo de dedicarse a la creación. Escritor prolijo y polifacético, tiene varios libros que rondan la treintena y sería exhaustivo enumerar: libros de viaje, ensayos, novelas, teatro, traducciones, artículos en diferentes periódicos y revistas. También ha prologado varios libros. En gran parte de sus escritos, su mayor preocupación es España como así lo demuestra algunos títulos de su producción: va España?, Lna dicladura en la Europa del siglo XX, España ante el mundo, ¿Qué es España?, etc.

No cabe la menor duda. de que estamos ante un español de talla universal, pero por esos inexplicables azares/avatares de la historia, ha pasado un tanto desapercibido, quizá eclipsado por esos "monstruos" de la 
Generación de 1914: José Ortega y Gasset, Américo Castro, Claudio Sánchez Albornoz, entre otros. Cabe añadir la sombra aún vigente de la Generación del 98 que seguía en pleno apogeo creativo con Unamuno. Machado, Azorín, Baroja y Maeztu.

La labor de todo investigador es rendir justicia, en la medida de sus posibilidades, e intentar recuperar del olvido a personajes que han tenido voz y voto en la época que les ha tocado vivir.

Según mis conocimientos, el único trabajo que se ha hecho sobre la persona de M. Domingo, es un estudio que hace hincapié en su catalanidad (La catalanitat de Marcel-lí Domingo) (1). Exceptuando este trabajo su figura yace en el olvido. Esto no se corresponde con la relevancia política y honestidad intelectual de que nos ha dejado un rico testimonio, como a continuación vamos a poder comprobar.

A nuestro juicio este escritor, que ha marcado parte de la vida pública española de su época, ha sido ante todo un hombre de acción. Siempre ha combatido por los principios democráticos, por la justicia y por el progreso de España. Ha sido un ferviente defensor y buen embajador de España en todos los lugares que ha visitado.

En su trayectoria política hay que resaltar algo importante: siempre ha sabido equilibrar su condición de catalán y español en una época en la que era fácil decantarse al extremismo.

Como podemos apreciar, a través de esta somera exposición biográfica, la vida de M. Domingo estará marcada por un período bastante convulso de la historia española. Llega a conocer el fracaso de la Restauración, la dictadura de Primo de Rivera, la Segunda República y la Guerra Civil, para luego morir en el exilio en la ciudad francesa de Toulouse el año 1939.

Hecha esta breve introducción biográfica a continuación vamos abordar el tema que nos ocupa:

"Marruecos en el pensamiento de Marcelino Domingo".

\section{MARRUBCOS EN EL PENSAMIENTO BSPAÑOL}

Marruecos ha sido una constante en la política y el pensamiento español, a lo largo de la historia. A este hecho han contribuido varios factores que se pueden sintetizar en los siguientes puntos. Primero; la proximidad geográfica que determina la vecindad: y todo lo que conlleva de conflicto o/y armonía. Y Segundo; la similitud etnogeográfica como así lo 
avalan los estudios demostrando que desde la Prehistoria el norte de Nfrica y la Península lbérica era una sola unidad con interferencias mutuas. En esta dirección cabe destacar la procedencia de un tronco común de bereberes e íberos. No es casual si la pintura rupestre del Levante español sea de similares características a la halladas en el norte de $\Lambda$ frica. El Mlediterráneo es un espacio de encuentro y reencuentro.

Marruecos y España arrastran un bagaje de historia común, no exenta de lagunas e incomprensiones, de guerras e invasiones, de diálogos y rupturas. Todos estos elementos tienen su justificación, en la tormentosa relación pacífico-bélica que ha marcado la historia de ambos países.

Generalmente, se suele tener como punto de referencia, el famoso Testamento de Isabel la Católica. a la hora de abordar el tema de Marruecos. Este Testamento es el que va a dar pie a toda una estrategia política de la Corona española de implantarse al otro lado de la orilla, con la idea de establecer una frontera contra posibles incursiones berberiscas.

La posterior expansión colonizadora de España hacia el sur: en la segunda mitad del siglo XIX y principios del XX, ha sido en parte motivada por ese legado histórico y responde a una motivación cuyo germen encontramos en el espíritu de la Reconquista.

Esto explica que el tema de Marruecos adquiera mayor relieve en la historia de España, sobre todo a partir de la segunda mitad del siglo XIX; pasando por la instauración del protectorado y la posterior independencia de Marruecos en 1956.

Al abordar un tema de similares características se encuentra uno un tanto desasistido: primero por la amplitud y la complejidad del tema; y segundo, el agravante de la carencia de estudios hechos al respecto. Los escasos -y meritorios- trabajos elaborados se reducen a meras aportaciones individuales en este terreno. Así lo confirman los trabajos de los hispanistas franceses Andrée Bachoud, Aubert, M. C. Lecuyer, Serrano. Y los españoles: Roberto Mesa. Miguel Martín, Ucelay de Calde, Víctor Morales Lezcano, Bernabé López García, etc.

\section{MARRUECOS Y MARCELINO DOMITGO}

Marruecos, ha sido un problema que a M. Domingo le ha tocado vivir en su época más conflictiva, por las circunstancias que rodearon el reparto de Africa. 
Esta es una de las razones que le han llevado a tratar el tema al igual que otros tantos intelectuales de su tiempo: Luis Araquistain. Julián Besteiro, Pablo Iglesias, Alejandro Lerroux. Francesc Cambó, Indalecio Prieto. Melquíades Alvarez, Vázquez de Mella, Ramiro de Maeztu. Camilo Barcia y un largo etcétera.

Pero ante todo hay que resaltar, que generalmente estos escritos responden más bien a opiniones. El tema de Marruecos no ha sido tratado de una manera coherente, sino siempre influenciado por condicionantes políticos y socio-históricos de la propia Península.

Entre la pléyade de intelectuales, destaca M. Domingo, porque ha sabido ver con bastante lucidez, espíritu crítico y una cierta coherencia ideológica el problema colonial.

\section{MARCELINO DOMINGO Y BL ABANDONO DE MARAUBCOS}

La idea de abandono es la que vertebra el ideario político de M. Domingo a la hora de abordar la problemática colonial marroquí. Es la idea que predomina.

Esta postura es un tanto lógica, si nos atenemos a la trayectoria política del diputado catalán. En una época en que. por una parte: tenemos el auge de los imperialismos: europeo y norteamericano: y: por otra: la profunda crisis política y económica de España. Esta doble coyuntura propiciará el fortalecimiento de unas izquierdas que empieza a tener peso específico y territorios que le son propios, entre los que destacamos: su.oposición a la aventura colonial.

El primer trabajo al que vamos a aludir, y en el cual se hace referencia a Marruecos es una conferencia, cuyo título es: "Liberalismo republicano", dada por M. Domingo en la sede de la "Joventut Republicana" de Lérida, el 30 de diciembre de 1911. En el transcurso de la misma dirá:

del mismo modo que se paraliza la guerra con Marruecos, mañana se cortaría definitivamente, supeditativamente, toda otra empresa aventurera, abandonando toda esia política de expansión, funesta para España, y concentrando todas las energias para la reconstitución interna del pais (2). 
He querido empezar con esta cita, porque me parece significativa por múltiples razones: Primero, la conferencia tiene lugar en Cataluña, región que siempre se ha mostrado combativa y contraria a la aventura marroquí. La Cataluña de principios de siglo, tenía una sociología política bastante sui generis: que le confiere un carácter especial a la hora de abordar temas de índole político-social. Como botón de muestra, tenemos la fuerte implantación anarquista cuyo sindicato la CNT llegó a tener un millón de afiliados. Y segundo, la fecha en que tiene lugar dicha conferencia es bien significativa, se sitúa a caballo entre la "Semana Trágica" de 1909 y 1912, fecha en que se firma con Francia el tratado del Protectorado sobre Marruecos.

La idea de abandono, será pues el leitmotiv principal sobre la que irá fraguando $M$. Domingo su estrategia política. Con sólo echar una breve ojeada a sus escritos políticos se percatará el lector de esta tendencia.

Uno de los libros clave para comprender la concepción de M. Domingo, relativo al tema del Protectorado, es el publicado en el año 1925, y cuyo título es de por sí atractivo y sugerente: :Qué es España.'. Este libro, que es una recopilación de artículos periodísticos aparecidos en la prensa de la época, será el más claro exponente, de su crítica a la situación política del momento.

Esta capacidad crítica se respira desde las primeras páginas. En el primer artículo, que lleva el título del libro, expone $\sin$ tapujos su idea abandonista y dice:

En la hora presente, España se halla ante un problema trágico en todos sus aspectos: el de Marruecos. Significa él la muerte de millares de hombres, el desnivel de la Hacienda del Estado, el descrédito en el mundo. ¿Qué actitud seria, resuelta decisiva se ha adoptado? Ninguna. No hay español que en la intimidad, en el círculo de sus relaciones, deje de pronunciarse contra los procedimientos seguidos en Marruecos o contra la permanencia en Marruecos; no existe español que, instintivamente o documentalmente, no esté convencido del desastre que la acción de Marruecos significa para España (3). 
La idea de abandono, es por lo tanto una idea a la que recurre, de manera constante a la hora de criticar la política gubernamental. Esta no responde a ningún oportunismo político; sino más bien a un ideal supremo que emanaba de su formación cultural y vivencial. Así lo explicita en una cita en la que dice:

Desde el primer día sostuvimos que abandonar no era equivalente a huir, sino que abandonar significaba, ayer, denunciar los tratados y parlamentar nueramente con las potencias que los signaron con España; hoy; acudir con el mismo propósito ante la Sociedad de Naciones encomendando a ésta la solución en última instancia (4).

Se desprende de esta cita que el abandono por el que aboga M. Domingo, no es en ningún caso derrotismo, como se ha querido interpretar en la época.

La idea de abandono, venía también movida por una fuerte convicción en la "regeneración" de España. En definitiva, se puede decir que era una especie de foco o campo para aglutinar a las masas contra la política oficial.

M. Domingo, en su concepción sintetizaba, tanto el aspecto social como el jurídico legal de la cuestión. Se podrían multiplicar las citas para corroborar esta idea abandonista. Nos contentaremos para finalizar con este apartado, de hacer públicas unas declaraciones suyas que aparecen en el prólogo al libro de Gómez Hidalgo, Marruecos. La tragedia prevista.

A la pregunta: “qqué hacer?" ante el problema de Marruecos nos dirá lo siguiente:

Nuestra respuesta ante ella es categórica: abandonar el Norte de Africa. ¿Por qué? Primero: por la evidente, ostensible y probada incapacidad colonizadora de España. Segundo: por la exigüidad de nuestros capitales y por la represión completa de una emigración orientada hacia Marruecos. Tercero: por la imposibilidad de una acción fuera de sus dominios en un país que tiene el 60 por 100 de analfabetos, las tres cuartas partes del 
territorio sin cultivo, en abandono o entregados a la explotación extranjera la mayor parte de sus yacimienlos mineros, en descrédito su Constilución, en incumplimientos sus leyes civiles, en rebeldia los poderes obligados a la más estricta disciplinu. Cuarto: por no ser una línea estratégica una zona que es hostil al dominio y. que representaría en horas de peligro más un nuevo peligro que una garantía de defensa (5).

\section{GSPAÑA Y LA INCAPACIDAD COLONIZADORA}

El hecho de que M. Domingo opte por el abandono, no es gra1uito. Responde a una coyuntura y exigencias socio-históricas bien determinadas como hemos podido demostrar a lo largo del anterior apartado. Ia tesis abandonista le llevará a plantear otra cuestión no menos importante para el devenir histórico de España, que es su incapacidad colonizadora.

Esta incapacidad a la que alude viene del convencimiento, de que España había acabado su ciclo de política imperial con la pérdida de Cuba en el año 1898 y el fracaso de toda política colonial.

En realidad lo que propone nuestro autor, es un examen de conciencia ante el lenómeno colonial. La pregunta que se planteaba era la siguiente: ¿por qué ir a colonizar otras tierras cuando aquí está todo por hacer? En esta lrase-pregunta se puede resumir esa preocupación; la disyuntiva era bastante evidente: España era la verdaderamente necesitada de esos capitales que se malgastaban en aventuras coloniales. Todo esto se desprende de una cita que resulta bastante esclarecedora:

Es el problema -dice M. Domingo-de nuestra capacidad colonizadora y el de las disponibilidades del Tesoro público y el de una sangria que aumenta el caudal de la sangre que se va por las fronteras, y el de nuestro crédito nacional... Marruecos hace tiempo que ha puesto a prueba dos valores: el de la competencia del Estado español y. el de la dignidad civil de la nación española (6).

En otro artículo de libro antes citado :Qué es España?: “1898. 1909, 1921\%, M. Domingo sintetiza en estas tres fechas claves de la historia 
militar española, las derrotas sufridas por el aparato bélico español fuera de sus fronteras. 1898 es la fecha que pone fin a la presencia española en Hispanoamérica. No obstante España volverá a reincidir en los mismos errores: esta vez con otra aventura colonial cerca de sus costas: Marruecos.

No resisto a la tentación de aludir a una cita, que refleja bastante bien las tropelías cometidas por España en su "misión civilizadora" en Marruecos:

España - dice M. Domingo- irrumpe en Africa sin un concierto económico, sin un grupo de maestros e ingenieros dispuestos, sin un grupo de agricultores y mineros preparado, sin un ejército organizado para este fin, sin un general experto o un estadista que tuviera el problema de Marruecos en el alma, sin una carta geográfica siquiera del territorio que se pretendía ocupar, sin una emoción pública que fuera, a la vez, conocimiento de la obra que iba a emprenderse y pasión por ella... Entra España en Marruccos, como entró en Cuba: a ciegas y a locas. La aventura otra vez, y como remate de la aventura, la tragedia (7).

La cita es muy elocuente, contiene - grosso modo- los reproches que las izquierdas le achacaban a los gobernantes, de la época: la primacía de lo militar sobre lo civil y humanitario. Este reproche será casi sistemático.

En definitiva, se puede decir que, la alusión a la incapacidad colonizadora, aparece casi siempre ligada, al tema del abandono. Es difícil delimitar un terreno del otro.

En consecuencia es la tesis del abandono quien lleva a cuestionar la incapacidad colonizadora de España. Así lo manifiesta, con sagacidad en otro libro cuyo título tampoco deja de llamar la atención: ja dónde va España? En un pasaje del mismo dice lo siguiente:

en abandonar Marruecos, campo abierto a todas las aventuras militares, sin otra justificación la casi tolalidad de ellas, que la necesidad doméstica o la fanfarronería de una recompensa; en abandonar Marruecos, cementerio y 
ruina de España, testimonio de la incapacidad civilizadora del Estado español, en su organización jurídica actual; en abandonar Marruecos, denunciando los Tratados ante la Sociedad de Naciones y ante las potencias que lo signaron con España; asi se daba la uinica solución que ya tiene el problema de Marruecos (8).

\section{INGAPACIDAD DBL BSTADO ESPAÑOL}

La idea de abandono y la incapacidad colonizadora de España dará pie a que se desate una campaña contra la máxima autoridad del Estado y la legitimidad del poder.

En el libro :Qué espera el Rey:?, publicado en el año 1918. M. Domingo dará cuenta del poder en España.

Para hacer un poco de historia diremos que el libro aparece en unas circunstancias un tanto especiales. Se publica tras la huelga de 1917 que conmocionó a todo el país y las consecuencias que ésta tuvo para M. Domingo con su encarcelamiento, a causa de sus artículos periodísticos. La huelga venía a ser un síntoma del fracaso y posterior desmoronamiento de la Restauración, cuya cabeza visible era el rey Alfonso XIII.

Todos estos factores han contribuido a que emergiera un sentimiento republicano; arropado en la idea de que la monarquía era un estado en decadencia, sentimiento que venía gestándose durante buena parte del siglo XIX para llegar en el siglo XX a su punto más álgido con el derrocamiento de la monarquía en el año 1931 y la instauración de la Segunda República.

La España de Marcelino Domingo era una España agitada socialmente y sobre todo, una España sin consenso, que es la base de toda estabilidad política. En el citado libro, deja entrever su crítica al régimen y sus simpatías por una sociedad republicana.

Para el líder catalán la institución monárquica, representaba el conservadurismo y la esclerosis social. Su libro es un alegato contra la monarquía y a todos aquellos que la sustentan: políticos, caciques, oligarcas, banqueros, etc. Al hablar de ello lo hará con estas palabras:

Para satisfacer el imperialismo real y asegurar la renta de algunos politicos y tener satisfechas las oligarquias que existen en el Ejército se declararon y continúan por 
años y años guerras como la de Marruecos. Y cuando contra el caciquismo o la falta de trabajo o contra el exceso de tributos o contra el mal gobierno o contra la guerra injusta se levanta un grito de dolor o de protesta, el grito es sofocado a balazos (9).

Para ahondar un poco en este tema basta decir que el pensamiento durante el primer tercio de este siglo está marcado por la dualidad: nación y Estado.

El maniqueísmo al que reducían la sociedad española, las izquierdas, era general, en aquel entonces. Este factor les permitía achacar todos los males que aquejaban al país, a su clase dirigente.

Como fruto de este contexto social no es extraño que M. Domingo piense que el problema colonial, sólo redunda en beneficio de la oligarquía terrateniente y del aparato militar. La nación por su parte, casi siempre se había mostrado contraria a la aventura marroquí.

Es ella, quien en última instancia padece las consecuencias en "oro y sangre".

Es imprescindible tener este trasunto social, si se quiere comprender los entresijos y la conflictividad política española de aquella época. De alí que $M$. Domingo se permita el calificar el imperialismo español de "real", en clara referencia al poder monárquico.

Así como somos de otra orden de caballeros sin calificación ministerial, somos también españoles de otra España. Nuestra España no calla ante la sangría de Marruecos: se revuelve; es capaz de hacer una sangría en la España del ministro de la Gobernación para acabar con la sangría de Marruecos. Nuestra España no se doblega ante los hombres del poder público: se subleva porque quiere otros hombres con manos más límpias, con frente más clara, con corazón más firme, con voluntad más recia. Nuestra España vital no se humilla ante la España oficial; al contrario: se incorpora para imponer la España vital a la España oficial; para hacer de la España vital la única España (10). 
A pesar de lo extensa de la cita, nos ha parecido interesante reproducirla en su totalidad porque sintetiza bastante bien. lo que acabamos de exponer, cuando evocábamos la dicotomía entre nación y Estado, que marcará el debate de esa época.

Esta situación que me atrevo a calificar de "disfunción social" tendrá una consecuencia trágica para España con la Guerra Civil de tristes recuerdos para todos.

En el artículo: "La definición de Costa", volverá a insistir en los mismos argumentos: la tragedia que supone Marruecos para España en todos los aspectos. Llega incluso a afirmar en un tono un tanto lacónico: "No hay Estado en España". Frase que refleja ese distanciamiento que mantenían los sectores de izquierdas con la política oficial. Resulta evidente que esta negación no implica en modo alguno inexistencia o ausencia del aparato estatal sino simplemente resaltar el abismo ideológico y la bipolarización de la sociedad española de aquella época.

"No hay Estado en España" significa que los verdaderos representantes del pueblo no están en el Parlamento. Y poner en evidencia la incapacidad del Estado a la planificación $y$ al desarrollo.

No es mera casualidad si el artículo evoca a Joaquín Costa, cuyo pensamiento tuvo gran influencia entre los intelectuales de principios de siglo.

\section{ESPAÑA POTBNCIA INFERIOR}

Un tema que enlaza con el anterior es el de la condición de España como pequeña potencia.

España no se podía codear con los imperialismos del momento. El grado de desarrollo alcanzado por éstos a nivel industrial y económico confería a estas potencias una supremacía que sigue siendo vigente hasta la época actual. La maquinaria industrial les empujaba a la conquista de mercados en el exterior y proveerse de materias primas y la exportación de sus productos manufacturados.

Sin embargo España se encontraba en decadencia, tras el desastre del 98. Esta fecha es clave porque en cierta medida marca el declive de un imperialismo anacrónico y la aparición sobre la escena internacional de otro tipo de imperialismo mucho más agresivo y económico.

En un artículo un tanto irónico titulado: "Rodrigonas de la historia", M. Domingo hace un parangón entre España y Grecia y dice: "El 
Essado griego cumple en Turquía designios de Inglaterra, de la misma manera que España cumple designios de Inglaterra en Marruecos" (11).

Este planteamiento le lleva a profundizar más en el asunto y argumenta, que tanto Grecia como España cumplen un mandato "impues10" por Inglaterra. En cierta medida son potencias al servicio de otra superior. Grecia y España son países interpuestos dentro de una coyuntura cuyo rasgo más destacado es el conflicto larvado entre Francia e Inglaterra.

A la hora del reparto del territorio marroquí entre Francia y España, Inglaterra desde la sombra, hizo todo lo posible para que España se quedara con la parte norte de Marruecos, para que el país galo no tuviese acceso a la orilla noroccidental del Mediterráneo. Estaba en juego su dominio sobre el Estrecho.

Esto dio pie a que Inglaterra moviera los hilos de la diplomacia a fin de que España se quedara con el litoral. Así nos lo explica M. Domingo:

A Inglaterra le conviene que en el Norte de Africa no se asiente ninguna gran potencia ofensiva, y escoge a España para que sea en el Norle de Africa la pequeña potencia inofensiva (12).

La anomalía de esta situación hace que Marcelino Domingo la critique porque no tolera el que España sea gendarme de otra potencia superior. No ve con buenos ojos el papel "celestinesco" que le ha tocado desempeñar.

España - dice M. Domingo en otra cita- está en el Norte de Africa, no por el testamento de Isabel la Católica, ni por compromisos históricos ni por imperativos de honor: está porque es una pequeña potencia inofensiva. Está, porque siendo una pequeña potencia inofensiva, no es un obstáculo ni un peligro para la política imperialista de Inglaterra (13).

La condición de potencia inferior, tendrá también sus repercusiones a la hora de aplicarlo al terreno de la economía: "en España -dice 
M. Domingo - nos resignamos a ser conquistados por todos - económicamente España es hoy una colonia-; pero no nos atrevemos a confesarlo" (14).

\section{MARRUBCOS Y CUBA}

El tema de Marruecos en el pensamiento de M. Domingo tendrá como fondo histórico-colonial inmediato el de Cuba.

En un libro publicado a principios de los años 20: La isla encadenada, en clara alusión al país caribeño, a raíz de un viaje efectuado por tierras Hispanoamericanas.

Desde el mismo instante en que toma el barco para emprender el viaje, $M$. Domingo evoca a aquellos soldados que embarcan con destino a Marruecos tras la derrota de Anual. He aquí cómo nos lo explica:

El buque nos aleja de España en las horas en que Espana alinea su juventud para embarcarla toda hacia Marruecos, y gasia cantidades fabulosas en el sostenimiento de la acción militar, y adopta, ella, la metrópoli civilizada, ante la colonia incivil, una actitud de rabiosa venganza (15).

El paralelismo entre su partida en barco y la de los soldados la trasbasa a otra dimensión de mucha más envergadura, estableciendo otro paralelismo: entre la guerra cubana del 98 y la de Marruecos del 21.

En otro orden de cosas esto le lleva a identificar al general Chinchilla, último gobernador español en La Habana, con el malogrado general Silvestre desaparecido en Anual el año 21. Viendo que la actitud de ambos jefes militares:

Revelan las dos la misma disposición de espíritu en los hombres representativos que España pone al frente de sus colonias. No han cambiado con los años los procedimientos; 1921 es lo mismo que 1890 (16).

La franqueza y honestidad de M. Domingo le hace opinar en consecuencia y dice a la hora de abordar la persona del caudillo rifeño Abdelkrim Al Jattabi: "es un problema que el Estado español se ha creado" 
(17); y que en su rebeldía ha tenido mucho que ver el comportamiento de los militares españoles para con los rifeños.

Llega incluso a ensalzar la figura de Abdelkrim y dice que éste: "ha sido hasta hoy el caudillo de la insurrección, la gran figura revolucionaria del mundo islámico" (18).

Otro de los temas que abordará $\mathrm{M}$. Domingo y que sólo mencionaremos a vuelapluma, es el tema de las Responsabilidades y las repercusiones que éste tuvo en la política española del momento. Era partidario de exigir responsabilidades a todos los culpables de la catástrofe acaecida en Anual.

Las responsabilidades tuvieron gran incidencia en la política española hasta tal punto que fueron determinantes para el advenimiento de la Dictadura del general Primo de Rivera quien con su golpe de Estado pondrá fin a este enojoso expediente.

\section{CONCLUSIONES}

Son varias las conclusiones que se pueden sacar aunque éstas nunca son definitivas dado el carácter intrínseco a toda labor investigadora. No obstante se pueden adelantar las siguientes:

1") Se trata de un pensador que se encuadra dentro del pensamiento democrático español.

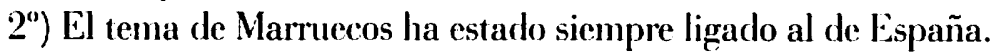

$\left.3^{\circ}\right)$ La influencia de Joaquín Costa y su vigencia en el pensamiento de M. Domingo.

$\left.4^{\circ}\right)$ Su alán por la mejora de España, tanto a nivel exterior como interior. Opinaba que la proyección exterior debe ser una consecuencia de la "regeneración" de España.

$\left.5^{\circ}\right)$ No hemos pretendido dar juicios de valor.

6") M. D. reúne en su persona características difíciles de aunar en un hombre político: honestidad y claridad.

$\left.7^{\circ}\right)$ Por su capacidad crítica es un coetáneo unestro a pesar del medio siglo que nos separa de su desaparición.

8") Y finalmente resaltar la claridad de las citas. Pero aún así el discurso de M. D. nos parece un tanto ambiguo en la medida de que la postura abandonista no la llevó hasta sus últimas consecuencias. 
1. DOMINGO, M.: La calalanital de Marcel-li Domingo, recop. Josep M. Polilet, Teide, Barcelona, 1978, 329 p.

2. DOMIN(, M.: Liberolismo republicano. Imp. Joventut, Lírida, 1911, p. 21.

3. DOMINCO, M.: i Qhé es España:, Allíntida, Madrid: 1925; pp. 7-8.

4. DOMINCO, M.: Libertad y' autoridad, Javier Morata, Madrid, 1928, p. 169.

5. COMEZ IIDALCO, F.: Marruecus. La tragedia previsła, pról. M. Domingo, linpr. Juan Pueyo, Madril, 1921, pp. 21-22.

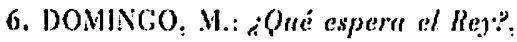
Javier Mornta, Madrid: 1930, p. 8

7. DOMINGO, M.: op. cit.. p. ??.
8. DOMINGO, M.: :A dónde va España:, Pról. G. Marañón, Historia Nueva, Madrid, 1930, 1.. 202.

9. DOMINGO. M.: ¿Qué esperu el key: j. 16.

10. DOMINGO, M.: op. cit., 63 .

11. DOMINCO, M.: op. cil... p. 11.

12. DOMINGO, M.: op. cit., pp. 67-68.

13. DOMINGO, M.: op., ciı.. p. 68.

14. DONIXGO, V.: op., cit., p. 42.

15. DOMINGO, Y.: La isler encadenarla, Mundo Latino, Madrid, p. 41.

16. DONINCO, M.: op.. cil., p. 45.

17. DOMINCO, M.: Libertad... p. 172.

18. DOMINGO, M.: op., cil.. 179. 